\title{
ÍNDICE DE SÍTIO PARA Pinus elliottii Engelm, EM TRÊS UNIDADES DE MAPEAMENTO DE SOLO, NAS REGIÕES DA SERRA DO SUDESTE E LITORAL, NO ESTADO DO RIO GRANDE DO SUL, BRASIL
}

\author{
SITE INDEX FOR Pinus elliottii Engelm, IN THREE SOIL MAPPING UNITS IN THE \\ SOUTHEASTERN MOUNTAIN RANGE AND COASTAL PLAIN AT RIO GRANDE DO SUL, BRAZIL \\ Helio Tonini ${ }^{1}$ César Augusto Guimarães Finger ${ }^{2} \quad$ Paulo Renato Schneider $^{3} \quad$ Peter Spathelf $^{4}$ \\ RESUMO
}

Realizou-se um estudo do crescimento em altura dominante de Pinus elliottii em povoamentos com idades entre 18 e 21 anos, localizados em três Unidades de Mapeamento de Solo, em quatro municípios, nas unidades de relevo Serra do Sudeste e Planície Gaúcha, no estado do Rio Grande do Sul. Os pares de dados altura e idade, oriundos de análise de tronco, foram ajustados pelo modelo de Richards. A construção de curvas de índice de sítio para cada local, indicou que a tendência de crescimento entre os locais estudados foi semelhante, o que permitiu o seu agrupamento e a geração de um único conjunto de 9 curvas monomórficas para os índices de sítio de 6 a 30 m, tendo como idade de referência 18 anos.

Palavras-chave: Pinus elliottii, índice de sítio, crescimento em altura.

\begin{abstract}
Dominant height growth of Pinus elliottii was analized in four stands at ages between 18 and 21 years old on three mapping soil units in the southeastern mountain region and coastal plains of Rio Grande do Sul, Brazil. Dominant height and age data were fitted using the Richards function. The site index curves, which were established for each locality, indicated that there was no difference in growth between the localities. This allowed to group all the curves to a unique system of 9 monomorphic curves for the site index between 6 and $30 \mathrm{~m}$ at the reference age of 18 years old.
\end{abstract}

Key words: Pinus elliottii, site index, height growth.

\section{INTRODUÇÃO}

A madeira tem ocupado uma posição central nos interesses do homem desde os tempos mais remotos (para fazer utensílios e armas), aos atuais, com largo uso em construções, fabricação de papel, combustível, entre outros.

A produção de madeira depende do processo fotossintético em que, mediante a assimilação, as árvores transformam água e gás carbônico em substância orgânica, sendo o crescimento influenciado por fatores do meio ambiente, que são basicamente: climáticos, edáficos e topográficos.

A interação desses fatores sobre as plantas expressa a qualidade do sítio, e o conhecimento de como estes fatores influem no crescimento é de fundamental importância na introdução de espécies e na maximização do aproveitamento do local, pois árvores de uma mesma espécie apresentam, em função do sítio, crescimentos diferentes, sendo a qualidade do sítio definida para cada espécie ou grupos de espécies.

Uma vez que a interação dos fatores ambientais é expressa na vegetação, pode-se buscar parâmetros de crescimento que indiquem a qualidade do sítio na própria vegetação. Nesse sentido, a altura dominante é a variável dendrométrica mais utilizada para medir a qualidade do sítio, especialmente por não ser influenciada por desbastes por baixo e não ser afetada pela densidade do povoamento.

1. Engenheiro Florestal, Mestrando pelo Programa de Pós-Graduação em Engenharia Florestal, Centro de Ciências Rurais, Universidade Federal de Santa Maria, CEP 97105-900, Santa Maria (RS).

2. Engenheiro Florestal, Dr., Professor Adjunto do Departamento de Ciências Florestais, Centro de Ciências Rurais, Universidade Federal de Santa Maria, CEP 97105-900, Santa Maria (RS). finger@ccr.ufsm.br

3. Engenheiro Florestal, Dr., Professor Titular do Departamento de Ciências Florestais, Centro de Ciências Rurais, Universidade Federal de Santa Maria, CEP 97105-900, Santa Maria (RS).paulors@ccr.ufsm.br

4. Engenheiro Florestal, Dr., Professor Visitante no Programa CAPES/DAAD, Departamento de Ciências Florestais, Centro de Ciências Rurais, Universidade Federal de Santa Maria, CEP 97105-900, Santa Maria (RS).

Recebido para publicação em 01/06/2000 e aceito em 19/06/2002. 
O estudo das curvas de crescimento em altura, para um determinado povoamento, originam as curvas de índice de sítio que são fundamentais no planejamento florestal, servindo para orientar o inventário florestal; na construção de tabelas de produção; no estudo de variedades e espécies e na adoção de técnicas de manejo florestal.

Estudos sobre a caracterização dos sítios florestais por meio da altura dominante para povoamentos de Pinus spp., no Rio Grande do Sul, foram realizados por autores como Schneider (1999), Brasil (1989 a e b) e Selle (1993). No entanto, os povoamentos utilizados nesses estudos estavam localizados nas regi ões do Planalto e na Serra do Nordeste, não existindo estudos semelhantes para povoamentos localizados nas regiões da Serra do Sudeste e o Litoral.

Por existirem grandes áreas plantadas com Pinus elliottii nestas regiões, com uma indústra de base florestal já existente e com grande disponibilidade de áreas pra novos reflorestamentos, estudos sobre o crescimento, em função do sítio, para a Serra do Sudeste e o Litoral tem grande importância, sendo este trabalho realizado com seguintes objetivos: Descrever o crescimento em altura em função da idade para Pinus elliottii em diferentes unidades de mapeamento de solo; comparar o crescimento em altura nas Unidades de Mapeamento de Solo e determinar o número de curvas de índice de sítio necessárias para cobrir a variação existente no(s) local(ais).

\section{REVISÃO BIBLIOGRÁFICA}

\section{Caracterização da espécie}

Pait et al. (1991) descreveram que o Pinus elliottii var. elliottii tem, como região de ocorrência natural, o estado da Carolina do Sul até o oeste do estado da Lousiana, em uma estreita faixa próxima ao Oceano Atlântico, no sudoeste dos Estados Unidos. Em sua região de ocorrência natural ocupa uma área de 5,1 milhões de hectares, respondendo por cerca de $12 \%$ do estoque de madeira existente. A variedade densa, de menor importância para plantações comerciais, tem sua área de ocorrência natural limitada ao extremo sul da Flórida.

Segundo Lamprecht (1990), o Pinus elliottii como espécie heliófita de crescimento rápido, goza de alta competitividade em relação às gramíneas e arbustos lenhosos, atingindo alturas de 20 a 30 metros, (máximo de 40 metros), e um diâmetro à altura do peito de $60 \mathrm{a} 90 \mathrm{~cm}$, sendo que o sistema radicular pode penetrar no solo até uma profundidade maior que 5 metros. Segundo o autor, essa espécie tem preferência natural por solos ácidos e arenosos localizados sobretudo em baixadas e junto a cursos de água, bem como áreas com lençol freático próximo à superfície. Em locais mais secos, em seu ambiente natural, cede lugar ao Pinus palustris, passando a formar com este um mosaico de pequenos povoamentos puros e ralos.

A temperatura média anual na região de origem oscila entre 15 e $24^{0} \mathrm{C}$, e os índices de precipitação variam de 650 a $2500 \mathrm{~mm}$, com um período seco de, no máximo, 4 meses, sendo considerada uma espécie bastante resistente às geadas e amplamente tolerante a ventos com elevados teores de sal, Lamprecht (1990).

Fisher apud Pait et al. (1991) descreveu os parâmetros de solo mais associados com o bom crescimento em altura para o Pinus elliottii, indicando que geralmente áreas planas mal-drenadas, e áreas ocasionalmente alagadas como beira de lagoas rasas e pântanos são os melhores sítios.

\section{Classificação de sítios}

Para Clutter et al. (1983), os métodos para predizer o crescimento de florestas são baseados no conceito de que o crescimento e a produção de povoamentos de uma dada espécie ou composição de espécies são influenciadas por quatro fatores: a) Idade do povoamento ou a distribuição da idade em povoamentos inequiâneos; b) A capacidade inata de produção da área envolvida; c) a suposição de que essa capacidade inata tem sido e é plenamente utilizada; d) Tratamentos silviculturais aplicados.

Davis (1966) citou a definição de sítio dada pela Sociedade Americana de Engenheiros Florestais, como uma área considerada segundo os seus fatores ecológicos em relação à sua capacidade de produzir florestas ou outra vegetação sob a combinação de condições biológicas, climáticas e edáficas. 
Para Gerdin e Schlatter (1995), nos estudos de classifica ção de sítios, deve-se analisar a dependência da produtividade em função de um conjunto de variáveis de sítio de distinta natureza para destacar as mais significativas. Para uma melhor interpretação dos resultados, é conveniente agrupar tais variáveis em conjuntos que caracterizem determinadas condições de sítio, sendo tais grupos de variáveis denominados de fatores de sítio.

No entanto, os fatores de sítio não são somente interdependentes, mas também são parcialmente dependentes da floresta que é a principal formadora de fatores de sítio. Em conseqüência dessas interações, as técnicas que estimam a qualidade do sítio por meio da avaliação de alguns fatores considerados os mais importantes, podem fornecer somente aproximações, pois somente considerando a floresta e o sítio como um ecossistema complexo interrelacionado será possível compreender plenamente a dinâmica natural (Spurr ]e Barnes, 1973).

A classificação de sítios pode ser ampla ou específica, diferenciando-se pelo grau de especificidade, condicionado geralmente pelo número de fatores influentes no sítio analisado. $\mathrm{O}$ aspecto amplo inclui classificações grosseiras de sítio, estabelecendo zoneamentos para grandes regiões, com grandes intervalos de classe, sendo as espécies estudadas pela sua adaptabilidade climática, e em função de classificações gerais de solo. As determinações mais específicas incluem levantamentos mais apurados, e são feitas em nível de área de uma empresa ou dentro de zoneamentos mais amplos (Schneider, 1993).

Johnston et al. (1967) afirmaram que o principal problema na classificação de sítios para propósitos florestais está em encontrar fatores que sejam bons índices de crescimento e ainda que sejam ideais para mais de uma espécie.

Segundo esses autores, na prática, os fatores de sítio têm sido menos precisos como indicadores do crescimento potencial, do que predições baseadas em fatores de crescimento. Em conseqüência disso, a grande maioria das classificações seguem o segundo caminho, embora apareçam na literatura termos como classe de sítio e qualidade do sítio em classificações feitas sem considerar as características do sítio.

Para Clutter et al. (1983), os métodos de classificação de sítios podem ser divididos em diretos e indiretos, sendo que os métodos diretos requerem a existência atual ou no passado de espécies de interesse no local onde a qualidade será avaliada. Os métodos diretos dividem-se em: a) estimação pelo histórico da produção.; b) estimação baseada em dados de volume do povoamento; c) estimação baseada em dados de altura do povoamento. E, os métodos indiretos dividem-se em: a) estimação pelas relações inter-espécies; b) estimação pelas características da vegetação inferior; c) estimação pelos fatores topográficos, climáticos e edáficos.

Bauer apud Assmann (1970) questionava a classifica ção de sítios apenas por fatores de sítio, por ser difícil de ser em igualmente descritos por diferentes pessoas e, conseqüentemente, a combinação de diferentes fatores, em diferentes locais, poderia traduzir-se em diferentes respostas no crescimento.

$\mathrm{O}$ autor afirmou que se alguém empregar, na classificação de sítio de uma área experimental, fatores como exposição, profundidade do solo, umidade e outros, logo encontrará que a melhor escala para classificar o sítio se encontra na altura média do povoamento.

Eichorm e Gehrhardt apud Assman (1970) afirmaram que, se a altura média de dois povoamentos são semelhantes, ambos terão o mesmo volume em todas as classes de sítio. Gehrhardt, no entanto, ampliou esse conceito, considerando o volume retirado nos desbastes, ou seja, a produ ção total, também como uma função da altura média.

A altura média, porém, apresenta o inconveniente de ser influenciada pelos desbastes aplicados, sendo necessário utilizar-se a altura dominante em substituição à altura média em tabelas de produção.

A altura dominante é a variável dendrométrica que melhor se enquadra aos requisitos propostos por Burger (1976), que são: a) facilidade de determinação a campo; b) possuir boa correlação com a produção volumétrica; c) indicar a qualidade do sítio para todas as idades do povoamento; d) ser independente da densidade do povoamento.

Diversas são as definições de altura dominante presentes na literatura, entre as quais, a altura média 
das cem árvores mais grossas por hectare (Assmann), a altura das árvores mais grossas correspondentes a $12 \mathrm{~m}^{2}$ de área basal por hectare (Pollanchutz), a altura correspondente ao dap médio de $20 \%$ das árvores mais grossas por hectare (Weise), entre outras.

Segundo Carmean (1970), o índice mais utilizado para determinar a produtividade de uma área florestal é o índice de sítio que é uma expressão da qualidade do sítio baseada na altura das árvores dominantes e codominantes em uma determinada idade índice.

Clutter et al. (1983) afirmaram que muitos usuários das curvas de índice de sítio acreditam erroneamente que o seu objetivo é a predição das alturas do povoamento até uma idade índice, sendo que o verdadeiro objetivo é a seleção de padrões de crescimento em altura que se espera que o povoamento assuma durante toda a sua vida. Segundo os autores, os dados para o desenvolvimento de equa ções de índice de sítio são obtidos basicamente de três fontes: a) medições de alturas em parcelas temporárias; b) medições de alturas em parcelas permanentes; c) reconstrução da relação altura/idade para árvores individuais mediante técnicas de análise de tronco.

No primeiro caso, parcelas temporárias são locadas na população de interesse, e a altura de árvores apropriadas em uma determinada idade são medidas em cada parcela. As parcelas temporárias são consideradas o método mais barato de obtenção de dados para a confecção de curvas de índice de sítio, porém, o uso destes dados envolvem o pressuposto que todos os índices de sítio estão representados em todas as classes de idade, o que geralmente é falso, pois sítios bons produzem volume mais rapidamente do que sítios ruins e, portanto, atingem um determinado volume mais cedo, o que implica em uma rotação mais curta e uma super-representação dos piores sítios nas maiores classes de idade.

Finger (1988) afirmou que, na busca de garantir o pressuposto de represe ntatividade dos índices de sítio nas classes de idade, devem-se coletar os dados de altura/idade, estratificando as unidades amostrais sobre diferentes sítios naturais previamente definidos na população, sendo esse método conhecido como linhas de tendência de crescimento.

As remedições de parcelas permanentes e a análise de tronco proporcionam dados com praticamente a mesma qualidade, sendo que a análise de tronco apresenta a vantagem de disponibilizar os dados imediatamente, o mesmo não acontecendo com as parcelas permanentes onde os dados ficam disponíveis somente após um determinado período de tempo a partir da instalação das parcelas Clutter et al., 1983).

Para Girardin e Broquen (1995), os povoamentos, que devem ser eleitos, a fim de que se possa utilizar a altura dominante como indicadora das condições de sítio, devem atender aos seguintes pré-requisitos: a) a população a ser amostrada não deve encontrar-se no estado juvenil de crescimento, pois, nesse estágio, o crescimento é muito variável e pode ser afetado por outros fatores que não a qualidade do sítio; b) as densidades não devem ser extremas, devendo estar entre 900 e 2500 árvores por hectare, de forma que garanta que não afetem a altura dominante. c) práticas silviculturais que tenham removido árvores dominantes não devem ter sido realizadas. d) o estado sanitário deve ser bom, e as árvores dominantes não podem ter sofrido danos severos.

As curvas de índice de sítio podem ser monomórficas ou polimórficas. As curvas monomórficas caracterizam-se por apresentar a mesma forma e guardar a mesma proporção para as diferentes classes de índice de sítio. Já as curvas polimórficas apresentam diferentes formas para cada classe de sítio e não guardam proporção nessas classes (Aguilar, 1997).

Davis (1966), Carmean (1970), Spurr e Barnes (1973), entre outros, afirmaram que assumir uma mesma forma de crescimento para todas as classes de sítio, nem sempre é verdadeiro e pode levar a erros de estimação, pois as árvores podem ter curvas altura/idade bastante diferentes e mesmo assim atingir a mesma altura (e índice de sítio) na idade índice.

Carmean (1970) afirmou que as curvas de índice de sítio, baseadas em análise de tronco para as principais espécies nos Estados Unidos, apresentavam um crescimento em altura polimórfico. Observou que árvores de carvalho localizadas em sítios ruins começavam a crescer mais lentamente em altura a partir dos 25 anos, enquanto árvores em sítios bons mantinham um crescimento linear por 50 anos ou mais. Essa observação levou o autor a concluir que a maioria das árvores tem um rápido crescimento inicial em sítios 
Índice de sítio para Pinus elliottii Engelm, em três unidades de mapeamento de solo ...

mais pobres, sendo portanto, o crescimento inicial um mau indicador do crescimento para anos posteriores.

Para Neto et al. (1996), o índice de sítio é o método mais utilizado para definir a potencialidade dos sítios florestais e, assim, o será até que métodos que conjuguem a soma de fatores ambientais possam ser traduzidos de forma numérica acessível aos usuários do setor.

\section{MATERIAL E MÉTODO}

\section{Localização das áreas de estudo}

As áreas selecionadas para a realização deste estudo situam-se nos municípios de Encruzilhada do Sul, Piratini, Palmares do Sul e Mostardas, no Rio Grande do Sul.

Os municípios de Encruzilhada do Sul (coordenadas $30^{\circ} 33^{\prime}$ de latitude sul e $52^{0} 30^{\prime}$ de longitude oeste) e Piratini (Coordenadas $31^{0} 25^{\prime}$ de latitude sul e $53^{\circ} 05^{\prime}$ de longitude oeste), localizam-se na região denominada Planalto Sul-Rio-Grandense que abrange uma área de $46.742 \mathrm{Km}^{2}$ e encontra-se limitada ao norte, leste e sudeste pela Depressão Central Gaúcha e a Oeste e sul pela Planície Gaúcha.

Os municípios de Palmares do Sul (coordenadas $30^{\circ} 00^{\prime}$ de latitude sul e 50 $50^{\circ}$ de longitude oeste) e Mostardas (coordenadas $30^{\circ} 05^{\prime}$ de latitude sul e $50^{\circ} 55^{\prime}$ de longitude oeste) localizam-se na região denominada Planície Gaúcha que abrange uma área de $41.594 \mathrm{~km}^{2}$, limitando-se ao norte com a Depressão Central, ao oeste com o Planalto Sul Rio Grandense e a leste e sul com o Oceano Atl ântico.

\section{Geomorfologia e relevo}

A unidade de relevo Planalto-Sul-Rio-Grandense caracteriza-se por apresentar uma estrutura geológica formada por rochas pré-cambrianas, apresentando relevos intensamente dissecados e áreas com relevos fracamente dissecados.

As áreas que correspondem aos relevos mais elevados com altitude ao redor d os 400 metros, onde se localizam os municípios de Encruzilhada do Sul e Piratini, apresentam-se dissecadas em forma de colina. As áreas mais intensamente dissecadas estão posicionadas altimetricamente entre as cotas 100 e 200 metros.

A Unidade de Relevo Planície Gaúcha devido, em razão da sua grande extensão e diversificados ambientes de depósitos sedimentares, foi dividida em três setores: a) Planície Marinha; b) Planície lagunar; c) Planície aluvio-coluvionar.

Os municípios de Palmares do Sul e Mostardas localizam-se na planície Marinha que ocupa aproximadamente $40 \%$ de toda a Planície Gaúcha onde as ações marinha e eólica são mais evidentes e o relevo é formado por um litoral retilíneo e costa com forma alongada (Herrmann e Rosa, 1990).

\section{Climatologia e edafologia}

Segundo a classificação de Köppen, o clima predominante nas áreas em estudo é do tipo Cfa (mesotérmico subtropical com verões quentes e sem estação seca). De acordo com Nimer (1990), o Planalto Sul-Rio-Grandense e a Planície Gaúcha apresentam uma precipitação média anual de $1500 \mathrm{~mm}$, sendo a temperatura média anual para o primeiro $16^{\circ} \mathrm{C}$ com um número médio de geadas igual a 10 , e para o segundo $18^{\circ} \mathrm{C}$ com um número médio de geadas igual a 1 .

A área em estudo no município de Encruzilhada do Sul, segundo Lemos et al. (1973), pertence à Unidade de Mapeamento Ibaré que ocupa uma área de $1,545 \mathrm{~km}^{2}$, representando $0,6 \%$ da área do Estado. Esta Unidade de Mapeamento se caracteriza por apresentar solos litólicos Eutróficos, com mais de $15 \mathrm{~cm}$ de espessura, bem-drenados, com textura média e desenvolvidos partindo de Xisto; O horizonte A apresenta uma espessura de 15 a $40 \mathrm{~cm}$, com textura franca e estrutura em blocos subangulares.

A área em estudo no município de Piratini é classificada por Lemos et al. (1973), como Unidade de Mapeamento Pinheiro Machado que ocupa uma área de $6.000 \mathrm{~km}^{2}$ e representa 2,22\% da área do Estado. Esta Unidade de Mapeamento é constituída predominantemente por solos litólicos distróficos, bem-drenados, de coloração escura, apresentando textura média, sendo derivado de granito. orgânica.

Geralmente são solos ácidos, com saturação e soma de bases média, sendo bem-providos de matéria

Para os municípios de Palmares do Sul e Mostardas, as áreas em estudo foram classificadas como 
pertencentes à Unidade de Mapeamento Curumin, ocupando uma área de $1.020 \mathrm{~km}^{2}$, representando $0,38 \%$ da área do Estado. Os solos, nessa unidade, são formados por areias quartzosas hidromórficas distróficas, profundos, mal a imperfeitamente drenados derivados de sedimentos arenosos costeiros. São considerados fortemente ácidos, com soma e saturação de bases baixa e com altos teores de alumínio trocável.

\section{Características das florestas e obtenção dos dados}

Os dados utilizados neste estudo foram obtidos em povoamentos implantados com Pinus elliottii, distribuídos sobre idades que variaram de 18 a 21 anos, sendo que os locais de coleta dos dados foram: a) no município de Encruzilhada do Sul, as árvores-amostra com 20 anos de idade foram retiradas de um povoamento implantado com um espaçamento inicial de $2 \times 2,5 \mathrm{~m}$, tendo sido realizado um desbaste ao $15^{0}$ ano. b) no município de Piratini, as árvores com 18 anos de idade foram retiradas de um povoamento implantado com um espaçamento inicial de $2 \times 2$ metros, tendo sido realizado um desbaste ao $12^{0}$ ano. c) na faixa litorânea, as árvores-amostra foram retiradas em povoamentos com 18 e 21 anos, tendo sido realizado um desbaste ao $12^{0}$ e $14^{0}$ ano respectivamente, ambos implantados com espaçamento inicial de 2,5 X 1,6 m.

Nos povoamentos localizados nos municípios de Encruzilhada do Sul e Piratini, as árvores foram coletadas segundo um gradiente de declividade: árvores de platô (solos eluviais), árvores de encosta superior e encosta média (solos coluviais) e árvores de baixada (solos aluviais).

Para a planície gaúcha (litoral), as árvores foram coletadas seguindo um critério de produtividade, em que as áreas foram classificadas como de boa, média e baixa produtividade. Em cada ponto de amostragem, com o auxílio do relascópio de espelho de Bitterlich de banda estreita, foi instalada uma unidade amostral temporária, em que as árvores foram selecionadas com probabilidade proporcional ao seu diâmetro (amostra por contagem angular). O ângulo selecionado para esse levantamento foi o de $2^{0} 17^{\prime}$ '32', correspondente ao fator de área basal $(\mathrm{FAB})$ igual a quatro. Com a utilização desse fator, cada árvore selecionada em uma unidade amostral (ACA) representa uma área basal de $4 \mathrm{~m}^{2} / \mathrm{ha}$.

Em cada unidade amostral, foram medidos os diâmetros à altura do peito de todas as árvores localizadas no interior desta e a altura das árvores dominantes. As árvores dominantes foram definidas segundo o conceito de Pollanschütz, descrito por Finger (1992), como a altura média de Lorey das maiores árvores correspondentes a $12 \mathrm{~m}^{2}$ de área basal por hectare, tomados partindo das maiores árvores. Com base nessa definição, a árvore dominante selecionada para a análise de tronco foi a que apresentou o diâmetro à altura do peito intermediário entre as três árvores mais grossas na unidade amostral.

Em cada ACA, a árvore dominante selecionada foi abatida, e foram retiradas fatias do tronco nas posições $0,1 \mathrm{~m}, 0,5 \mathrm{~m} \mathrm{1,3} \mathrm{m}$ e partindo desta a cada $1,5 \mathrm{~m}$, procurando-se evitar os nós e as deformações causadas por estes nos anéis anuais de crescimento. Os pares de dados altura e idade foram obtidos por análise de tronco com a utilização do software ANATRO desenvolvido por Schneider (1984).

Neste estudo, foram coletadas 42 árvores dominantes, distribuídas em quatro diferentes locais, em diferentes posições do relevo e em áreas com diferentes produtividade, totalizando 730 pares de dados altura e idade. A distribuição das árvores em classes de altura, idade e local de coleta, é apresentada na Tabela 1,

TABELA 1: Distribuição das árvores de Pinus elliottii em classes de altura, idade e local de coleta.

TABLE 1: Distribution of Pinus elliottii trees in height and age classes for each locality.

\begin{tabular}{c|c|c|c|c|c|c|c}
\hline $\begin{array}{c}\text { Classe de Altura } \\
\text { (metros) }\end{array}$ & \multicolumn{3}{|c|}{ Idade (anos) } & \multicolumn{4}{c}{ Local } \\
\cline { 2 - 8 } & 18 & 20 & 21 & E & P & PA & M \\
\hline $15-16,9$ & 1 & - & - & - & - & 1 & - \\
$17-18,9$ & 1 & - & - & - & - & 1 & - \\
$19-20,9$ & 2 & 1 & 5 & 1 & 2 & - & 5 \\
$21-22,9$ & 4 & 3 & 4 & 3 & 4 & - & 4 \\
$23-24,9$ & 4 & 7 & 2 & 7 & 4 & - & 2 \\
$25-26,9$ & 2 & 3 & - & 3 & 2 & - & - \\
$27-28,9$ & 1 & 2 & - & 2 & 1 & - & - \\
\hline Total & 15 & 16 & 11 & 16 & 13 & 2 & 11 \\
\hline
\end{tabular}

Em que: $\mathrm{E}=$ Encruzilhada do Sul; $\mathrm{P}$ = Piratini; PA = Palmares do Sul; $\mathrm{M}=$ Mostardas. 
em que pode se observar que, das 42 árvores dominantes amostradas, quinze tinham 18 , dezesseis 20 e onze 21 anos de idade. Na mesma tabela, observa-se que 16 árvores foram coletadas no município de Encruzilhada do Sul, 13 em Piratini, 2 em Palmares do Sul e 11 em Mostardas.

O modelo utilizado para ajustar os dados de altura e idade para cada árvore dominante amostrada foi o de Richards (1959), com três coeficientes que são expressos por :

$$
h_{\text {dom }}=A \times\left(1-e^{(-k \times t)}\right)^{(1 /(1-M))}
$$

Em que: $\mathrm{h}_{\mathrm{dom}}=$ altura dominante; $\mathrm{t}=$ idade; $\mathrm{A}, \mathrm{K}$ e $\mathrm{M}=$ coeficientes do modelo.

\section{Procedimento para a construção das curvas de índice de sítio das localidades em estudo}

Após o ajuste da função de Richards (1959), utilizou-se a análise de covariância para detectar diferenças em inclinação e níveis entre as curvas de crescimento das árvores localizadas na mesma região e Unidade de Mapeamento e entre os locais estudados.

Para a construção das curvas de índice de sítio, utilizaram,-se os coeficientes médios $\mathrm{K}$ e $\mathrm{M}$ e estimou-se o coeficiente A que passa a ser obtido pela transformação do modelo matemático para uma altura desejada na idade índice, conforme apresentado por Finger (1991):

$$
A=\frac{I S}{\left(1-e^{(-K x t)}\right)^{(1 /(1-M))}}
$$

Em que: $\mathrm{A}=$ assíntota calculada; $\mathrm{IS}=$ índice de sítio; $\mathrm{K}, \mathrm{M}=$ coeficientes; $\mathrm{t}$ = idade índice; $\mathrm{e}=$ base do logaritmo natural.

A idade índice selecionada foi a de 18 anos, uma vez que nenhum dos povoamentos analisados apresentou uma idade inferior a essa, e, por essa idade estar mais perto da idade de rota ção média para tal espécie no sul do Brasil, considerada em torno dos 20 anos.

Em razão do sistema absoluto de classificação ser mais ilustrativo e ser o mais utilizado em classificações de sítio no Brasil, optou-se pelo seu emprego.

Para se testar a confiabilidade e a estabilidade na construção das curvas compararam-se graficamente as alturas reais com as curvas de índice de sítio para todas as árvores amostradas individualmente.

$\mathrm{Na}$ definição do número de curvas necessárias para cobrir a variação entre o menor e o maior crescimento em altura dominante observado na região, foram empregados pares de dados altura e idade medidos em 318 parcelas temporárias com diferentes idades oriundas de inventários florestais realizados nesses locais. Tais dados foram plotados com as curvas de índice de sítio, delimitando a sua abrangência.

\section{RESULTADOS E DISCUSSÃO}

\section{Características dendrométricas dos povoamentos.}

Os dados coletados nas Amostras por Contagem Angular (ACA'S), realizadas nos povoamentos de Pinus elliottii nos quatro municípios estudados (Tabela 2), mostram uma tendência de superioridade em termos de capacidade produtiva, para os povoamentos localizados na Serra do Sudeste (Encruzilhada do Sul e Piratini) em comparação com os localizados no Litoral. Essa tendência pode ser verificada analisando-se o número de árvores e a área basal média observadas nas ACA'S, em que se verifica que, mesmo com um maior número de árvores, o horto florestal localizado no Litoral 2 apresenta uma área basal bastante inferior ao localizado em Encruzilhada do Sul.

A altura dominante no horto florestal, localizado no Litoral 2, mesmo com idade superior aos localizados em Encruzilhada do Sul e Piratini, é inferior, sendo menor em 4,2 metros em relação ao primeiro e 3,3 em relação ao segundo.

A análise do incremento periódico para os últimos 7 anos, indica uma superioridade para o horto localizado em Piratini e Litoral 2, sendo que a superioridade em termos de incremento periódico para os 
povoamentos localizados no litoral em relação ao localizado em Encruzilhada do Sul, confirmando a teoria descrita em Assmann (1970), de que as maiores alturas atingidas em sítios melhores, devem-se aos maiores incrementos nas idades jovens, na fase juvenil e de pleno vig or.

TABELA 2: Valores médios de número de árvores por hectare $(\mathrm{N})$, área basal $(\mathrm{G})$, diâmetro à altura do peito (DAP), altura dominante $\left(\mathrm{h}_{\text {poll }}\right)$ e incremento periódico em altura para os últimos 7 anos $\left(\mathrm{Ip}_{7} \mathrm{~h}\right)$, observados nas amostras de contagem angular (ACA'S).

TABLE 2: Average values of the stem number/ha (N), basal área $(\mathrm{G})$, Diameter at breast height (DAP), dominant height $\left(\mathrm{h}_{\text {poll }}\right)$ and periodical height increment in the last seven years $\left(\mathrm{Ip}_{7} \mathrm{~h}\right)$ observed in the samples.

\begin{tabular}{lcccccc}
\hline \multicolumn{1}{c}{ Local } & $\mathrm{N}$ & $\mathrm{G}\left(\mathrm{m}^{2} / \mathrm{ha}\right)$ & $\mathrm{h}_{\text {poll }}(\mathrm{m})$ & $\mathrm{DAP}(\mathrm{cm})$ & $\mathrm{Ip}_{7} \mathrm{~h}(\mathrm{~m})$ \\
\hline Encruzilhada & 697 & 39,75 & 28,0 & 24,6 & 5,05 \\
Piratini & 892 & 40,80 & 25,2 & 23,7 & 7,06 \\
Litoral 1 & 646 & 21,50 & 21,5 & 18,0 & 5,95 \\
Litoral 2 & 780 & 26,69 & 22,8 & 20,4 & 6,08 \\
\hline
\end{tabular}

A altura dominante no horto florestal, localizado no Litoral 2, mesmo com idade superior aos localizados em Encruzilhada do Sul e Piratini, é inferior, sendo menor em 4,2 metros em rela ção ao primeiro e 3,3 em relação ao segundo.

A análise do incremento periódico para os últimos 7 anos, indica uma superioridade para o horto localizado em Piratini e Litoral 2, sendo que a superioridade em termos de incremento periódico para os povoamentos localizados no litoral em relação ao localizado em Encruzilhada do Sul, confirmando a teoria descrita em Assmann (1970), de que as maiores alturas atingidas em sítios melhores, devem-se aos maiores incrementos nas idades jovens, na fase juvenil e de pleno vigor.

\section{Ajuste do modelo matemático}

O ajuste dos dados de altura em função da idade, obtidos por análise de tronco de 42 árvores dominantes, com a utilização da função de Richards com três coeficientes, mostraram altos coeficientes de determinação $(0,99)$ e baixos valores de erro-padrão de estimativa em porcentagem $(0,98-10,55)$, conforme consta na Tabela 3.

TABELA 3: Resultados estatísticos obtidos no ajuste da função de Richards com três Coeficientes, altura real e estimada para os quatro locais estudados.

TABLE 3: Statistical results for the Richards function, real and fitted height to the four studied places.

\begin{tabular}{lcc|ccc|c}
\hline Local & Árvore & $\mathrm{R}^{2}$ & Syx $\%$ & Altura Observada $(\mathrm{m})$ & Altura Estimada $(\mathrm{m})$ \\
\hline Encruzilhada & 1 & 0,997 & 2,515 & 27,0 & 26,9 \\
Encruzilhada & 2 & 0,998 & 0,988 & 23,7 & 24,5 \\
Encruzilhada & 3 & 0,996 & 2,618 & 24,9 & 25,2 \\
Encruzilhada & 4 & 0,980 & 6,019 & 22,5 & 22,8 \\
Encruzilhada & 5 & 0,997 & 2,766 & 27,4 & 26,0 \\
Encruzilhada & 6 & 0,998 & 5,877 & 26,0 & 25,1 \\
Encruzilhada & 7 & 0,999 & 1,677 & 25,1 & 22,9 \\
Encruzilhada & 8 & 0,996 & 2,872 & 22,8 & 20,5 \\
Encruzilhada & 9 & 0,993 & 3,568 & 20,3 & 24,6 \\
Encruzilhada & 10 & 0,993 & 4,383 & 24,8 & 27,0 \\
Encruzilhada & 11 & 0,996 & 3,122 & 26,4 & 23,7 \\
Encruzilhada & 12 & 0,994 & 4,225 & 24,3 & 23,2 \\
Encruzilhada & 13 & 0,996 & 2,817 & 23,7 & 24,8 \\
Encruzilhada & 14 & 0,997 & 2,457 & 24,7 & 21,2 \\
Encruzilhada & 15 & 0,995 & 3,643 & 24,5 & 23,4 \\
Encruzilhada & 16 & 0,998 & 2,489 & 21,5 & 24,2 \\
Piratini & 1 & 0,996 & 2,705 & & \\
\hline
\end{tabular}


Tabela 3: Continuação ...

Table 3: Continued ...

\begin{tabular}{lccccc|c}
\hline Local & Árvore & $\mathrm{R}^{2}$ & Syx\% & Altura Observada $(\mathrm{m})$ & Altura Estimada $(\mathrm{m})$ \\
\hline Piratini & 2 & 0,997 & 2,512 & 26,7 & 26,5 \\
Piratini & 3 & 0,997 & 2,274 & 19,9 & 20,0 \\
Piratini & 4 & 0,997 & 2,781 & 22,6 & 22,6 \\
Piratini & 5 & 0,998 & 2,426 & 20,9 & 26,4 \\
Piratini & 6 & 0,979 & 7,653 & 27,2 & 24,3 \\
Piratini & 7 & 0,998 & 4,969 & 24,5 & 22,9 \\
Piratini & 8 & 0,995 & 3,045 & 22,8 & 22,4 \\
Piratini & 9 & 0,995 & 3,201 & 22,2 & 22,0 \\
Piratini & 10 & 0,993 & 3,351 & 23,7 & 22,9 \\
Piratini & 11 & 0,997 & 2,921 & 22,9 & 21,5 \\
Piratini & 12 & 0,992 & 4,213 & 22,0 & 23,4 \\
Piratini & 13 & 0,996 & 2,917 & 23,9 & 15,2 \\
Palmares & 1 & 0,998 & 2,034 & 15,4 & 18,8 \\
Palmares & 4 & 0,998 & 6,888 & 18,3 & 20,6 \\
Mostardas & 2 & 0,997 & 2,799 & 16,1 & 22,1 \\
Mostardas & 3 & 0,995 & 3,429 & 21,6 & 21,1 \\
Mostardas & 5 & 0,996 & 2,975 & 21,7 & 19,7 \\
Mostardas & 6 & 0,995 & 2,982 & 21,6 & 18,7 \\
Mostardas & 7 & 0,989 & 5,589 & 20,5 & 19,5 \\
Mostardas & 8 & 0,962 & 10,566 & 19,6 & 20,5 \\
Mostardas & 9 & 0,996 & 2,564 & 19,1 & 21,8 \\
Mostardas & 10 & 0,997 & 2,677 & 20,5 & 22,2 \\
Mostardas & 11 & 0,996 & 3,151 & 22,3 & 18,8 \\
Mostardas & 12 & 0,996 & 2,791 & 22,9 & \\
Mostardas & 13 & 0,997 & 2,775 & 19,0 &
\end{tabular}

Em que: $\mathrm{R}^{2}=$ Coeficiente de determinação; Syx\% = Erro-padrão da estimativa em porcentagem.

A análise gráfica dos resíduos mostrou que o ajuste do modelo ao longo de toda a amplitude dos dados observados não foi tendencioso, o que é de grande importância para a confiabilidade das estimativas.

\section{Procedimento para a construção das curvas de índice de sítio}

O estudo de funções auxiliares pelo procedimento stepwise, para descrever a rela ção entre os coeficientes A, K e M da equação de Richards (1959), com a altura da árvore na idade índice conforme apresentado por Clutter et al. (1983), Sterba e Oberkofler (1988) e Selle (1993), não revelou nenhuma correlação entre as variáveis dependentes e independente, nas formas logaritma, aritmética, quadrática e inversa.

Não existindo regressão entre os coeficientes e a altura na idade índice selecionada, as curvas de crescimento de cada árvore-amostra foram comparadas quanto ao paralelismo pela análise de covariância.

\section{Comparação do crescimento entre locais}

A comparação do crescimento em altura dominante para os locais estudados foi feita pela análise de covariância. Uma vez que foram coletadas apenas duas árvores dominantes no município de Palmares do Sul, os dados dessas árvores foram agrupados com as árvores coletadas em Mostardas.

O resultado da análise de covariância mostrou que a hipótese de igualdade de inclinação das curvas de crescimento é rejeitada ao nível de $5 \%$ de erro, nos diferentes locais, indicando a não-ocorrência de paralelismo entre as curvas de crescimento em altura das árvores (Tabela 4). Da mesma forma, os resultados obtidos com o teste de Tukey, ao comparar médias entre os diferentes locais para 95\% de probabilidade, indicaram a formação de grupos distintos de árvores contendo diferenças significativas entre os locais estudados. 
TABELA 4: Análise de covariância para testar a paralelismo das curvas de crescimento da altura dominante para os locais estudados.

TABLE 4: Covariance analysis to test the parallelism of the dominant height grow th curves to the studied places.

\begin{tabular}{l|r|c|c|cc}
\hline \multicolumn{1}{c}{ FV } & GL & SQ & QM & F & Prob. > F \\
\hline Coeficientes & 3 & 25495,6021 & 8498,5340 & 3880,07 & 0,0001 \\
Local & 2 & 1631,0575 & 815,5287 & 372,34 & 0,0001 \\
Idade x Local & 2 & 185,7916 & 92,8958 & 42,4123 & 0,0001 \\
Erro & 725 & 1587,9688 & 2,1903 & - & - \\
\hline Total & 732 & 28900,42 & - & - & - \\
\hline
\end{tabular}

Em que: $\mathrm{FV}=$ Fonte de variação; $\mathrm{GL}=$ Graus de liberdade; $\mathrm{SQ}=$ Soma dos quadrados; $\mathrm{QM}=$ Quadrado médio; $\mathrm{F}=$ valor de $\mathrm{f}$ calculado.

Embora a análise estatística tenha indicado diferenças entre a inclinação das curvas, tal diferença é pequena, resultando em curvas muito próximas, conforme se verifica na Figura 1, ao se analisarem as tendências de crescimento em alturas obtidas por meio das curvas de índice de sítio construídas separadamente para os três locais.

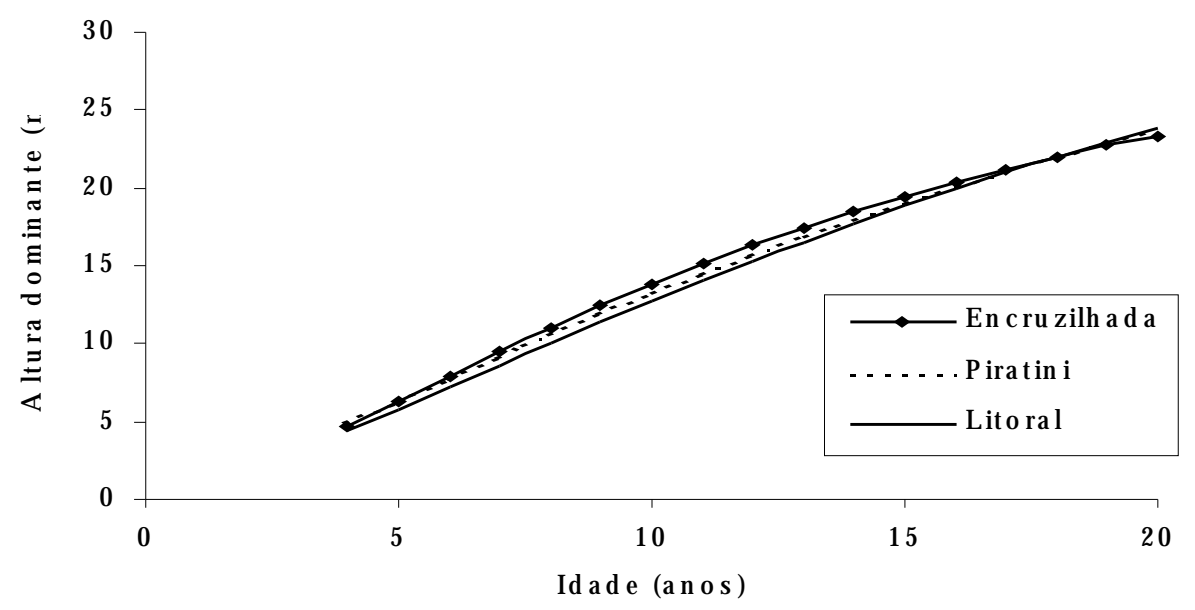

FIGURA 1: Comparação entre as curvas de índice de sítio (IS 21) construídas individualmente para cada local estudado.

FIGURE 1: Site index curves comparison built for each studied place.

A análise dessa figura mostra que a tendência de crescimento entre os três locais foi semelhante, sendo que, para um mesmo índice de sítio, existe uma leve superioridade no crescimento em altura para as árvores de Encruzilhada do Sul. No entanto, a diferença máxima encontrada entre tais curvas foi de 0,64 m, estando dentro dos erros cometidos ao se medirem as alturas no campo, justificando o emprego de um único conjunto de curvas monomórficas para os três locais estudados. Dessa forma, as curvas foram construídas utilizando a média dos coeficientes K e M para todas as árvores amostradas.

\section{Confiabilidade e estabilidade das curvas de índice de sítio.}

Os testes de confiabilidade e estabilidade das curvas de índice de sítio feitos plotando-se as alturas reais sobre as curvas de índice de sítio, permitiram avaliar graficamente o comportamento das árvores quanto a uma eventual mudança de índice ao longo do tempo, bem como avaliar a confiabilidade de se efetuar classificações em idades mais jovens. (Figura 2). 

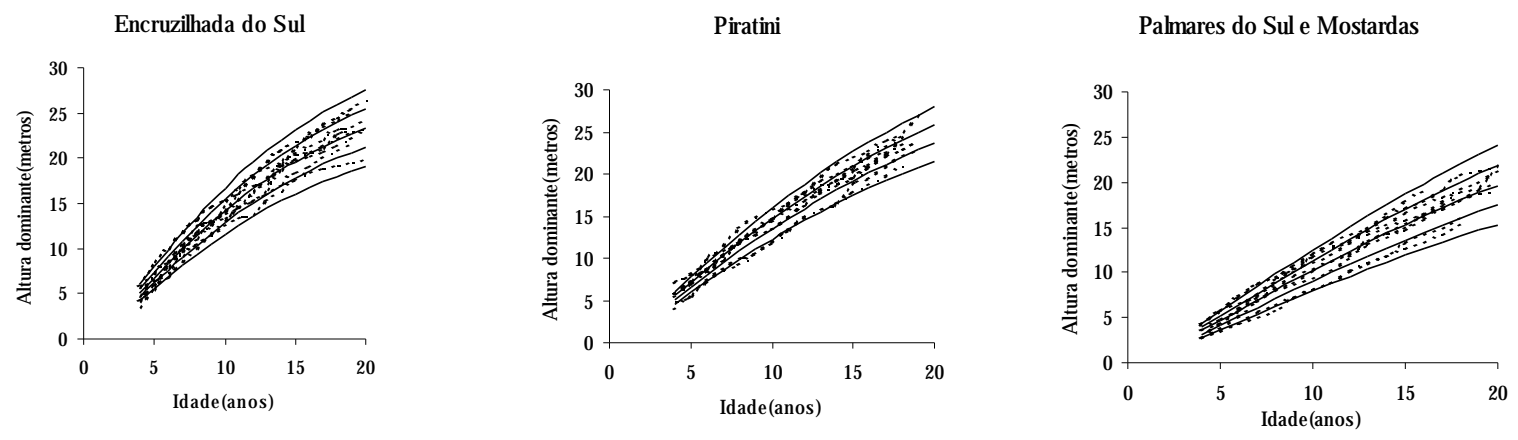

FIGURA 2: Estabilidade das curvas de índice de sítio para árvores de Encruzilhada do Sul, Piratini e Palmares do Sul/Mostardas.

FIGURE 2: Estability of the site index curves for Encruzilhada do Sul, Piratini and Palmares do Sul/ Mostardas.

\section{Determinação do número de curvas para cobrir a variação de sítios}

Os pares de dados altura dominante e idade, obtidos de medições de parcelas temporárias feitas na região em estudo foram plotados sobre as curvas de índice de sítio e indicaram a necessidade de construir um sistema de 9 curvas com intervalo de 3 metros, abrangen do índices de sitio de 6 a 30 metros (Figura 3 e Tabela 6).

Pela análise da Figura 3, observa-se uma grande variação de sítios. Os piores sítios foram observados no litoral onde aparecem exclusivamente os índices de sítio 6 e 9.

TABELA 6: Valores das curvas de índice de sítio entre as idades de 4 a 20 anos.

TABLE 6: Values of the site index curves among the ages from 4 to 20 years.

\begin{tabular}{c|c|c|c|c|c|c|c|c|c}
\hline \multirow{2}{*}{ Idade } & \multicolumn{10}{c}{ Índice de sítio } \\
\cline { 2 - 9 } & 6 & 9 & 12 & 15 & 18 & 21 & 24 & 27 & 30 \\
\hline 4 & 1,20 & 1,81 & 2,41 & 3,01 & 3,62 & 4,23 & 4,82 & 5,42 & 6,02 \\
5 & 1,61 & 2,41 & 3,21 & 4,02 & 4,83 & 5,63 & 6,43 & 7,24 & 8,04 \\
6 & 2,01 & 3,02 & 4,03 & 5,04 & 6,05 & 7,06 & 8,06 & 9,07 & 10,09 \\
7 & 2,42 & 3,63 & 4,84 & 6,06 & 7,27 & 8,48 & 9,69 & 10,91 & 12,12 \\
8 & 2,82 & 4,23 & 5,64 & 7,06 & 8,47 & 9,87 & 11,29 & 12,70 & 14,11 \\
9 & 3,21 & 4,81 & 6,42 & 8,03 & 9,63 & 11,24 & 12,84 & 14,45 & 16,05 \\
10 & 3,58 & 5,38 & 7,16 & 8,96 & 10,80 & 12,55 & 14,34 & 16,13 & 17,92 \\
11 & 3,94 & 5,91 & 7,88 & 9,86 & 11,80 & 13,81 & 15,78 & 17,75 & 19,72 \\
12 & 4,28 & 6,43 & 8,57 & 10,72 & 12,90 & 15,01 & 17,15 & 19,29 & 21,44 \\
13 & 4,61 & 6,92 & 9,22 & 11,54 & 13,80 & 16,15 & 18,46 & 20,77 & 23,07 \\
14 & 4,92 & 7,38 & 9,84 & 12,31 & 14,80 & 17,24 & 19,70 & 22,16 & 24,62 \\
15 & 5,21 & 7,82 & 10,43 & 13,04 & 15,70 & 18,26 & 20,87 & 23,48 & 26,09 \\
16 & 5,49 & 8,24 & 10,98 & 13,74 & 16,50 & 19,23 & 21,98 & 24,72 & 27,47 \\
17 & 5,75 & 8,63 & 11,51 & 14,39 & 17,30 & 20,14 & 23,02 & 25,90 & 28,78 \\
18 & 6,00 & 9,00 & 12,00 & 15,00 & 18,00 & 21,00 & 24,00 & 27,00 & 30,00 \\
19 & 6,23 & 9,34 & 12,46 & 15,57 & 18,70 & 21,80 & 24,92 & 28,03 & 31,15 \\
20 & 6,44 & 9,66 & 12,89 & 16,11 & 19,30 & 22,56 & 25,78 & 29,00 & 32,23 \\
\hline
\end{tabular}

Esses sítios são comuns em planossolos onde o relevo permite o excesso de água, fazendo com que a má drenagem seja um fator limitante para a produ ção nestas áreas, no entanto, a presença de sítios médios (IS 21 e 24), no litoral, é um indicativo de que solos arenosos com baixa profundidade do len çol freático podem ser produtivos para a espécie estudada.

$\mathrm{Na}$ Serra do Sudeste, mesmo com a predominância de solos litólicos com baixa profundidade de perfil e presença de afloramentos rochosos, percebe-se a presença de sítios melhores na comparação com o 
litoral, uma vez que os índices de sítio 27 e 30 ocorrem exclusivamente nessa região. Este resultado, de certa forma, confirmam as afirmações de Van Goor (1967), de que a profundidade do solo não é um fator limitante em clima sem inverno muito seco.

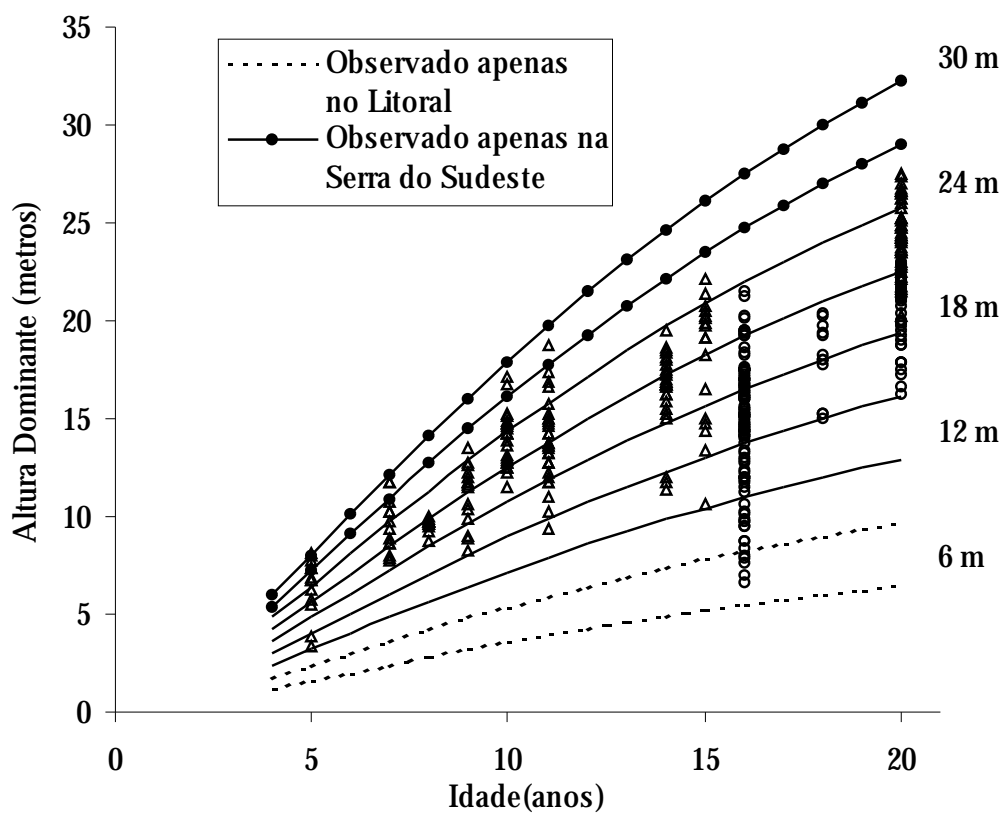

Em que: $\bullet$-altura dominante observada no Litoral; $\Delta$-altura dominante observada na Serra do Sudeste

FIGURA 3: Curvas de índice de sítio para a Serra do Sudeste e o Litoral.

FIGURE 3: Site index curves for southeastern mountain region and littoral.

\section{CONCLUSÕES}

De acordo com os resultados obtidos neste estudo, pode-se concluir:

a) A função de Richards com 3 coeficientes descreveu, com precisão, o crescimento em altura dominante para todas as árvores analisadas;

b) a tendência do crescimento em altura dominante mostrou-se semelhante para as três unidades de mapeamento estudadas o que justificou a construção de um único sistema de curvas monomórficas;

c) os piores sítios foram encontrados no Litoral, e os melhores na regi ão da Serra do Sudeste.

\section{AGRADECIMENTOS}

Os autores agradecem as Empresas Forjasul Ltda., localizada no munic ípio de Encruzilhada do Sul; Germina Agroflorestal Ltda., localizada no município de Piratini e a Florestadora Palmares Ltda., localizada no município de Palmares do Sul, no Rio Grande do Sul, pela permissão para o levantamento dos dados e abate das árvores em florestas de sua propriedade, sem as quais não seria possível a realização deste trabalho.

\section{REFERÊNCIAS BIBLIOGRÁFICAS}

AGUILAR, R. M. Estudio del crescimiento de Pinus douglasiana Martínes y Pinus lawsonii Roezl en la región central de Michoacán. Revista Ciência Florestal en México, v .22, n. 81, p.42-70,1997.

ASSMANN, E. The principles of forest yield study. Oxford: Pergamon Press, 1970. 506p.

BRASIL Plano de manejo para a Floresta Nacional de Passo Fundo-RS. Santa Maria: UFSM, 1989a.

BRASIL Plano de manejo para a Floresta Nacional de São Francisco de Paula. Santa Maria: UFSM, 1989 b. 
BURGER, D. Ordenamento florestal I. 2. ed. Curitiba: UFPR, 1976. não-paginado.

CARMEAN, W. H. Tree-growth patterns in relation to soil and site. In: _. Tree growth and forest soils. Oregon State University, USA, 1970. 527p.

CLUTTER, J. L.; FORTSON, J. C.; PIENAAR, L.V. Timber management: a quantitative approach. USA: John Wiley \& Sons. 1983. 329p.

DAVIS, K. P. Forest managment, regulation and valuation. USA: Mc Graw Hill, 1966. 519p.

FINGER., C. A.G. Ein Beitrag zur Ertragskunde von Eucalyptus grandis und Eucalyptus saligna in Südbrasilien. 1991. 136p. Tese (Doutourado) - Universität für Bodenkultur, Wien.

. Fundamentos de biometria florestal. Santa Maria: UFSM, 1992. 269p.

Crescimento e produção florestal. 1998. Notas de aula na disciplina de crescimento e produção florestalPrograma de Pós-graduação em Engenharia Florestal.

GERDING, V.; SCHLATTER, J. E. Variables y factores del sitio de importancia para la productividad de Pinus radiata D.Don en Chile. Bosque, v. 16, n. 2, p. 39-56, 1995.

GIRARDIN, J. L.; BROQUEN, P. El crecimiento de Pinus ponderosa Dougl. y Pseudotsuga menziessii Mirb. en diferentes condiciones de sítio. Bosque, v. 16, n. 2, p. 57-67, 1995.

HERRMANN, M. L. P.; ROSA, R. Relevo. In: FUNDAÇÃO INSTITUTO BRASILEIRO DE GEOGRAFIA E ESTATÍSTICA. Geografia do Brasil: Região Sul. Rio de Janeiro, 1990. p. 59-83.

JOHNSTON, D. R.; GRAYSON. A, J.; BRADLEY. R. T. Forest planning. London: Russel Square, 1967. 529p.

LAMPRECHT, H . Silvicultura nos trópicos: ecossistemas florestais e respectivas espécies arbóreas - possibilidades e métodos de aproveitamento sustentado. Tradução de Guilherme de Almeida Sedas e Gilberto Calcagnotto. Rossdorf: TZ-Verl.-Ges, 1990. 343p.

LEMOS et al. Levantamento de reconhecimento dos solos do Estado do Rio Grande do Sul. Recife, 1973. 431p.

MARCOLIN, M. Polimorfismo e tamanho da amostra para construção de curvas de índice de sítio para Pinus taeda L., no Segundo Planalto Paranaense. 1990. 57p. Dissertação (Mestrado em Engenharia Florestal) Universidade Federal do Paraná, Curitiba.

NETO, F. R. C.; SCOLFORO, J. R. S.; OLIVEIRA, A. D. et al. Uso da diferença algébrica para construção de curva de índice de sítio para Eucalyptus grandis e Eucalyptus urophylla, na região de Luiz Antonio-SP. Cerne, Lavras , v. 2, n. 2, p. 119-141,1996.

NIMER, E. Clima. In: FUNDAÇÃO INSTITUTO BRASILEIRO DE GEOGRAFIA E ESTATÍSTICA. Geografia do Brasil: Região Sul. Rio de Janeiro, 1990. p. 151-187.

PAIT, J. A.; FLINCHUM, D. M.; LANTZ, C. W. Species variation, allocation, and tree improvement. In: __. Forest regeneration manual. London: Kluwer Academic Publishers, 1991. p. 207-231.

RICHARDS, F.J. A flexible growth function for empirical use. J. Agr. Pres, v. 46, n. 7 p. 62-638, 1959.

SCHNEIDER, P. R. ANATRO: Programa de computador, ambiente MS-DOS. Santa Maria, 1984.

. Introdução ao manejo florestal. Santa Maria: UFSM, 1993. 348p.

.Tabelas auxiliares para o manejo de Pinus elliottii e Araucaria angustifolia para a região do Planalto Médio do Rio Grande do Sul. Santa Maria: UFSM, 1999. 118p.

SCOLFORO, J. R. S, MACHADO, S. A. Curvas de índice de sítio para plantações de Pinus elliottii nos Estados do Paraná e Santa Catarina. Revista Floresta, Curitiba, v. 17, p. 140-158, 1988.

SELLE, G. L . Influência dos fatores ambientais na classificação de sítio para Pinus taeda L, na região de Cambará do Sul, RS, Brasil. 1993. 85 p. Dissertação (Mestrado em Engenharia Florestal) - Centro de Ciências Rurais, Universidade Federal de Santa Maria, Santa Maria.

SPURR, S. H, BARNES, B. V. Forest ecology. New York : Ronald Press Company, 1973. 571p.

STERBA, H, OBERKOFER, H. Das Wachstum der Fichte im Pustertal Forstliche Ertragslehre der Universitat für Bodenkultur. Wien, 1988. 55p.

VAN GOOR, C. P. Reflorestamento com coníferas no Brasil, aspectos ecológicos dos plantios na Região Sul, particularmente com Pinus elliottii e Araucaria angustifolia no Estado de são Paulo. Silvicultura em São Paulo, v. 4, n. 4-5, p. 349-366, 1967. 